\title{
Knowledge And Awareness On The Association Between Physical Inactivity, Junk Food Consumption And Obesity Among Adolescent Population - A Survey Based Analysis
}

Chithambara Shathviha Palaniappan ${ }^{1}$, Karthik Ganesh Mohanraj ${ }^{*}$, Mebin George Mathew ${ }^{3}$

${ }^{1}$ Saveetha Dental College and Hospitals, Saveetha Institute of Medical and Technical Sciences, Saveetha University, Chennai, India.

${ }^{2}$ Assistant Professor, Department of Anatomy, Saveetha Dental College and Hospitals, Saveetha Institute of Medical and Technical Sciences, Saveetha University, Chennai, India.

${ }^{3}$ Assistant Professor, Department of Pedodontics, Saveetha Dental College and Hospitals, Saveetha Institute of Medical and Technical Sciences, Saveetha University, Chennai, India.

\section{Abstract}

\begin{abstract}
Aim: The aim of the study is for better perception of association between physical inactivity consumption of junk food among middle childhood and adolescent population.

Background: Junk foods are empty calories. An empty calorie of lakhs in micronutrients such as vitamins, minerals or amino acids,and fibre but has high energy.Increasing awareness about the risks of junk food consumption during adolescence is an important step for the prevention of lifestyle diseases like obesity.

Materials and Methods: A sample size of 100 statistics is analysed with a cross sectional survey taken up on a behaviour data questionnaire for parents and students of middle childhood and adolescents. Data analysis done in SPSS software with statistical test student's unpaired T test results are determined. The data collection was done during April 2020 and the time period of data analysis was April 2020 to May 2020.

Result: About $85 \%$ of the population are aware about the physical inactivity and consumption of junk food and its harmful effects leading to obesity.

Conclusion: The present study highlighted the association between physical inactivity and consumption of junk food leading to obesity. This survey created a basic awareness among the middle childhood and adolescent populations about the harmful effects and related physical inactivity status due to consumption of junk food which in turn leads to obesity.
\end{abstract}

Keywords: Junk Food; Unhealthy Diet; Obesity; Harmful Effects; Health Problems.

\section{Introduction}

The emerging trend among the young generation is consumption of fast food with a very less physical inactivity. Its consumption is often associated with negative impairment and on nutritional status and health [1]. The availability and taste made it popular among the middle childhood and adolescent population. The world's adaptation to fast food has become a global phenomenon. [2]. The junk food energy density has been found to be more than twice the effects on health [3]. The regular intake of junk food lacks energy,poor concentration,obesity,high cholesterol.The increased amount of time spent in sedentary behaviors has diminished the amount of physical activity time spent [4]. The types of food that are available in the house and the family members' food preferences will affect the food that children eat. Additionally, family mealtimes can influence the type and amount of food consumed. Lastly, family habits, whether they are sedentary or physically active, influence the child $[5,6]$. A mixed diet and physical activity plan with a school portion done in the community is more successful in reducing obesity or overweight. Additionally, if parents adopt a healthy lifestyle at home, many issues with obesity can be avoided.

Childhood obesity is evolving as a major public health issue which increases the risk of subsequent morbidity as a result of hypertension, type 2 diabetes mellitus, dyslipidemia, left ventricular hyper-

*Corresponding Author:

Karthik Ganesh Mohanraj,

Assistant Professor, Department of Anatomy, Saveetha Dental College, Saveetha Institute of Medical and Technical Sciences (SIMATS), Saveetha University, Chennai - 600 077, Tamil Nadu, Chennai.

Email ID: karthikm.sdc@saveetha.com

Received: February 25, 2021

Accepted: March 04, 2021

Published: March 09, 202

Citation: Chithambara Shathviha Palaniappan, Karthik Ganesh Mohanraj, Mebin George Mathew. Knowledge And Awareness On The Association Between Physical Inactivity, Junk Food Consumption And Obesity Among Adolescent Population - A Survey Based Analysis. Int J Dentistry Oral Sci. 2021;08(03):1946-1951. doi: http://dx.doi.org/10.19070/2377$8075-21000385$

Copyright: Karthik Ganesh Mohanraj ${ }^{\circ} 2021$. This is an open-access article distributed under the terms of the Creative Commons Attribution License, which permits unrestricted use, distribution and reproduction in any medium, provided the original author and source are credited. 
trophy, non-alcoholic steatohepatitis, obstructive sleep apnea, and orthopedic and psychosocial problems $[4,7]$. Obesity in adolescence is a significant risk factor for a range of serious non-communicable diseases in adulthood such as cardiovascular diseases, diabetes mellitus, osteoarthritis, gallbladder diseases, cancers with an increased risk of mortality [8-10].

The prevalence of obesity is increasing worldwide, it is faster in developing countries due to declining levels of physical activity as well as nutrition transition characterized by a trend towards consumption of a diet high in fat, sugar and refined foods and low in fibre $[11,12]$. It becomes important to educate children about healthy eating habits and to know about the factors influencing food choices and the awareness on fast food consumption and lack of physical inactivity $[10,13,14]$. This survey was done to assess the relationship between physical inactivity and consumption of junk food to make the middle childhood and adolescent population aware about the health hazard.

\section{Materials and Methods}

The study was conducted in an online setting among the Chennai population with approval of the Institutional review board obtained no human and animal ethical approval needed. A total of 100 samples were selected between the age group of 10-15 years and $15-18$ years. The sampling method is simple random sampling all variables are included. A pre tested questionnaire formulated for the collection of information. The questionnaire was simple and brief. The self made questions were developed. The general information where on the general profile, name, age, gender is collected.

The questionnaire included self made questions to assess about the physical inactivity and amount of junk food consumption. The frequency of consumption of junk food and the physical activity of individuals is assessed. Correlation analysis and chi- square tests were done and the results were statistically analysed. The data collection was done in April 2020 and the time period for data analysis was from April 2020 to May 2020.

\section{Results}

In our present study ,Figure 1 is showing the survey results obtained by the statistical analysis is discussed here, the participation by male is $40 \%$ and female is $59 \%$ in this survey. Figure 2 is showing the age group participation in the survey is 30\% of $10-15$ years and $69 \%$ of $15-18$ years.

Figure 3 is showing the consumption of favourite junk food categorised as $39 \%$ consume fast food and $27 \%$ consume snacks, $21 \%$ consume candies, $12 \%$ consume soft drinks as their favourite junk. Figure 4 shows that $89 \%$ of the population are aware about the chemicals present in the junk food and $10 \%$ of the population is not aware of the chemical hazard. Figure 5 shows that the frequency of intake is $44 \%$ of the population eats once a week, $39 \%$ eat twice a week and $16 \%$ eat more than twice a week. Figure 6 shows that $70 \%$ of participants assume that they are active enough even after consuming junk food and 29\% participants are doubtful about their activity.

Figure 7 is showing that $41 \%$ of participants agree that consumption of junk food reduces their physical activity and $32 \%$ disagree with this and $26 \%$ are confident about their physical activity. Figure 8 shows that the population in different circumstances experienced physical illness $41 \%$ had mild illness, $37 \%$ had moderate illness, $14 \%$ had severe illness, $4 \%$ had very severe physical illness. Figure 9 shows that the cause of obesity is agreed by $80 \%$ of the population and $94 \%$ are aware that physical inactivity will lead to obesity and $5 \%$ are not aware. Figure 10 shows that the population of the survey $71 \%$ agreed to control the consumption of junk food and $18 \%$ disagreed and $12 \%$ are doubtful.

Figure 1 Pie chart showing percentage distribution of gender in survey participants. $40 \%$ (blue) of the participants were male and $59 \%$ (green) of the participants were female. $\mathrm{N}=100$. Among the survey participants females were more.

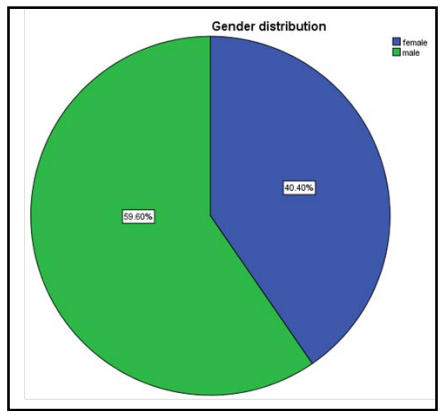

Figure 2. The pie chart showing percentage distribution of age in the survey participants. The age group 10-15 years were 30\%(blue) and age group 15-18 years were $69 \%$ (green). $\mathrm{N}=100$. The age group 15-18 years were more among the survey participants.

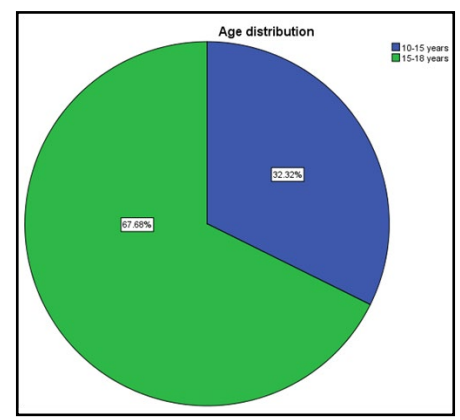


Figure 3. The pie chart showing the percentage distribution of favorite junk food in survey participants. $39 \%$ (blue) answered fast food, $27 \%$ (green) answered snacks, $21 \%$ (beige) answered candies and $12 \%$.(violet) answered soft drinks. $\mathrm{N}=100$.Majority of the respondents consume fast food.

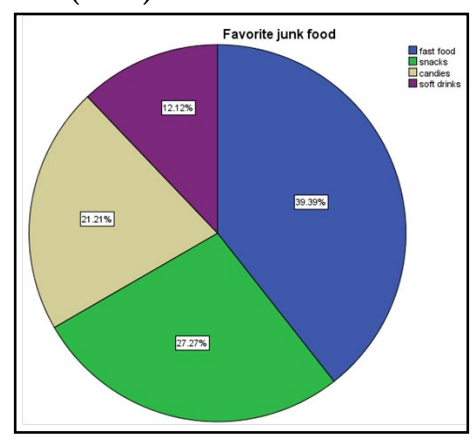

Figure 4. The pie chart showing the percentage distribution of responses on awareness on harmful effects of chemicals present in junk food. $89.90 \%$ (blue) answered yes and $10.10 \%$ (green) answered no. $\mathrm{N}=100$. Majority of the respondents are aware of the harmful effects and chemicals present in junk food.

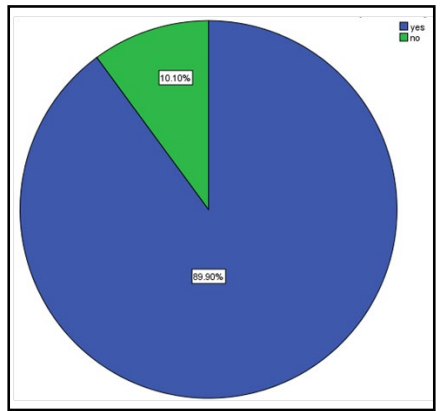

Figure 5. The pie chart showing the percentage distribution of participants on frequency of junk food consumption. Frequency of consumption once $44 \%$ (blue), frequency of consumption twice $39 \%$ (green), frequency of consumption more than thrice $16 \%$ (beige). $\mathrm{N}=100$. The frequency of intake once per week is more.

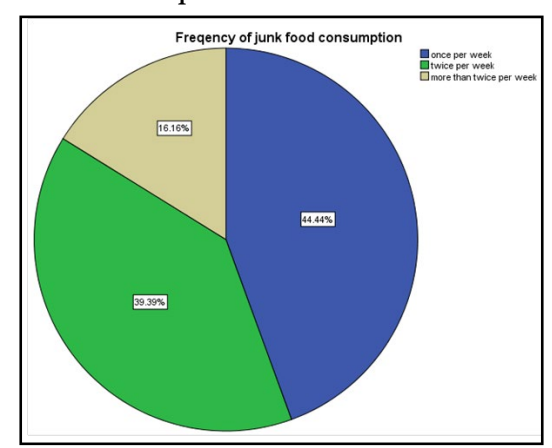

Figure 6. The pie chart showing the percentage distribution in physically active condition of participants upon consumption of junk food. Physically active after consumption of junk food $70 \%$ (blue) and physically not active after consumption of junk food $29 \%$ (green). N=100.Majority of participants are physically active.

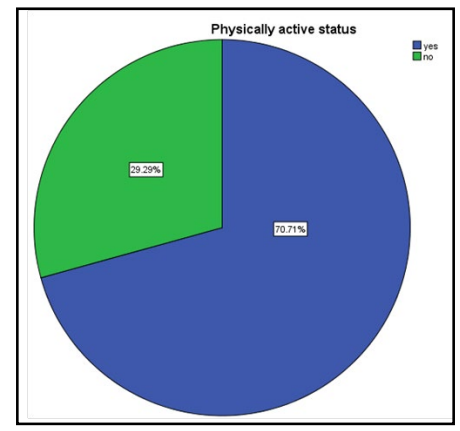

\section{Discussion}

Among the respondents $40 \%$ were male and 59\% were female and the age group response is $30 \%$ of age group were $10-15$ years and $69 \%$ of age group were $15-18$ years. In our study the prevalence rate of favorite junk fast food is $39 \%$ and similar findings were seen in the study conducted by [15] $41 \%$ consumed fast food, $21 \%$ consumed candies, $16 \%$ consumed snacks and 14\% consumed soft drinks. Large scale of middle childhood and adolescent population consume fast food.
The present study results consensus with the study conducted by [16] where $30 \%$ are aware about the chemical on junk food and $10 \%$ are unaware. Only less population is unaware of the harmful effects in consumption of junk food [17]. Similar study was conducted by $[18,19]$ where $49 \%$ are aware about the harmful effects of consumption of junk food and $6 \%$ are unaware of the harmful effects. The frequency of junk food consumption in adolescents is less comparatively. In the present study $70 \%$ of respondents are physically active and similar findings were seen in a study con- 
Figure 7. The pie chart showing the percentage responses of awareness on consumption of junk food on a daily basis reduces physical activity. Consumption of junk reduces physical activity: Yes - $41 \%$ (blue). Consumption of junk does not reduce physical activity: No - 32\%(green) Consumption of junk might reduce physical activity: May be $-26 \%$ (beige). $\mathrm{N}=100$.Majority of survey participants agree that consumption of junk food reduces physical activity.

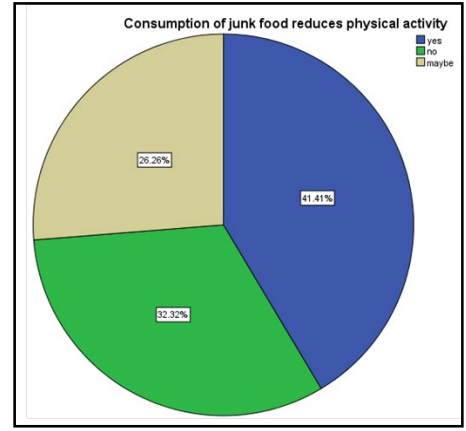

Figure 8. The pie chart showing the percentage distribution of responses on physical illness due to consumption of junk food. Mild physical illness 44\%(blue); Moderate physical illness 37\%(green); Severe physical illness 14\%(beige); Very severe physical illness $4 \%$ (violet). N=100.Majority of participants had mild physical illness.

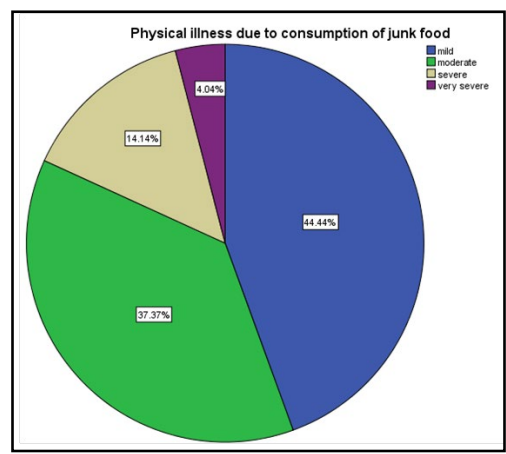

Figure 9. The pie chart showing percentage distribution of responses of participants having knowledge on lack of physical activity leading to obesity. Participants response - Agree 80\%(blue); Disagree $9 \%$ (green); Unaware $10 \%($ beige). $\mathrm{N}=100$. Majority of the participants agree that lack of physical activity leads to obesity.

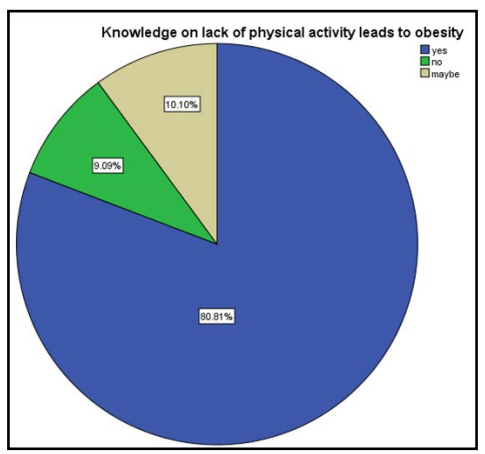

Figure 10. The pie chart showing the distribution of participant responses who are controlling the consumption of junk food. Agreed to control consumption of junk food $71 \%$ (blue); Disagreed to control consumption of junk food $16 \%$ (green); Might control consumption of junk in future $12 \%($ beige) $\mathrm{N}=100$. Majority of the survey participants agreed to control the consumption of junk food.

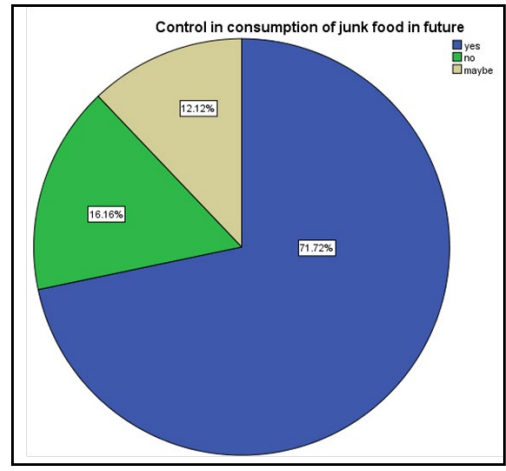


Figure 11. The bar graph represents the association between age and physical inactivity of the participants. $\mathrm{X}$ axis represents the age groups and $\mathrm{Y}$ axis represents the number of participants.This showed that more adolescents were physically inactive due to consumption of junk foods among the age group 15-18 years than 10-15 years but was not statistically significant. Chi square test showed $p=0.09$ (Pearson Chi square $p>0.05$ ) indicating statistically not significant.

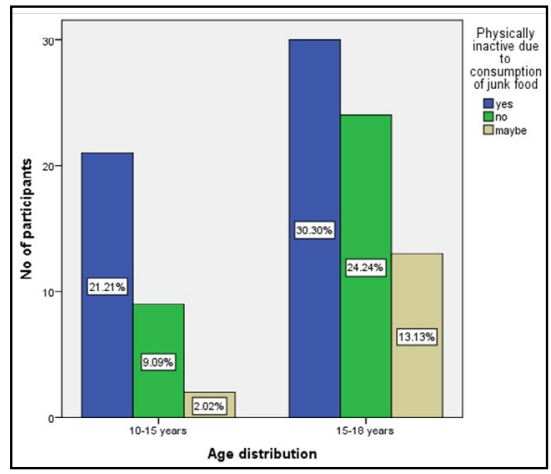

Figure 12. The bar graph represents the association between age and frequency of junk food consumption. The $Y$ axis represents the number of participants and the $\mathrm{X}$ axis represents the frequency of junk food consumption per week.Among the age group 15-18 years 67\% of the participants show high frequency of consumption of junk food.This shows that more adolescents consume junk food frequently than the age group of 10-15 years but was not statistically significant.Chi square test showed. $\mathrm{p}=0.15$ (Pearson Chi square; $\mathrm{p}<0.05$ ) indicating statistically significant.

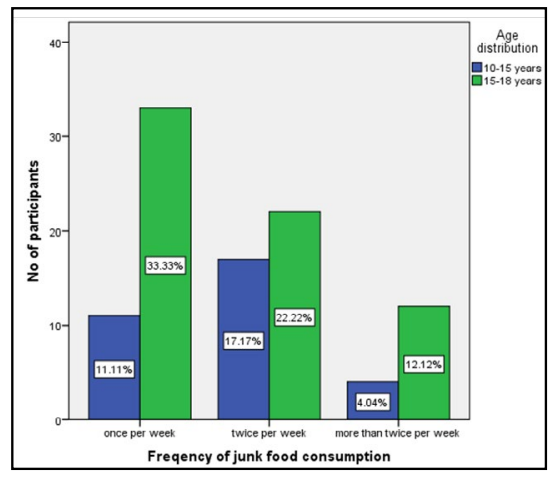

Figure 13. The bar graph represents the association between age and knowledge on lack of physical activity leads to obesity. The $\mathrm{X}$ axis represents the age groups and the $\mathrm{Y}$ axis represents the number of participants with frequencies of knowledge on physical activity leading to obesity. Among the participants more than $50 \%$ of age group $15-18$ years and $30 \%$ of age group $10-15$ years agree that lack of physical activity leads to obesity. Chi square test showed $\mathrm{p}=0.04$ ( Pearson Chi square $; \mathrm{p}<0.05$ ) indicating statistically significant.

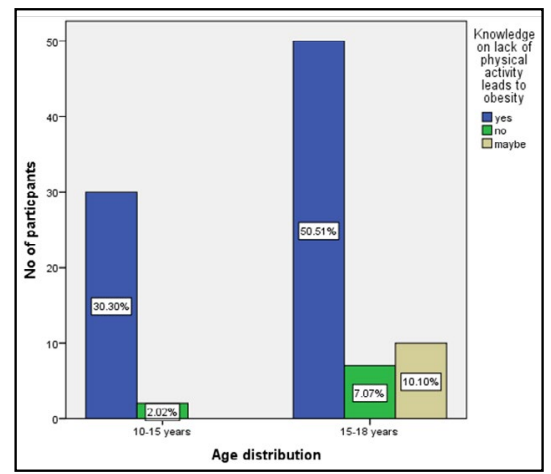

Figure 14. The bar graph represents the association between frequency of junk food consumption and physical illness. The $\mathrm{X}$ axis represents the frequency of junk food consumption and $\mathrm{Y}$ axis represents the number of participants. This shows that the participants in all frequencies of junk food consumption show more than $44 \%$ of mild physical illness which reveals frequent consumption of junk food leads to physical illness but not statistically significant. Chi square test showed $\mathrm{p}=0.58$ (Pearson Chi square; $\mathrm{p}<0.05$ ) indicating statistically not significant. More participants become physically ill mildly once in a week due to junk food consumption.

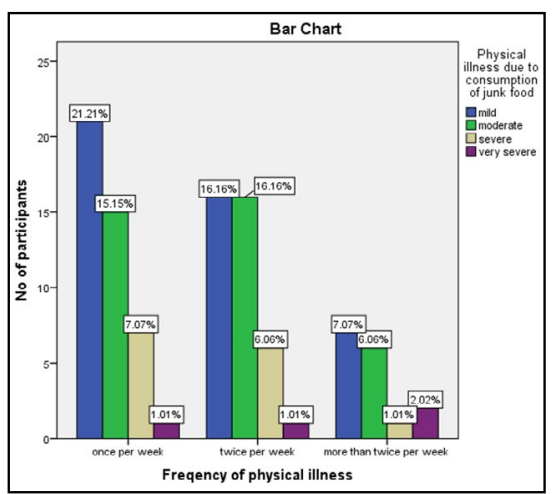


ducted by [20] where $65 \%$ assume they are physically active and $20 \%$ are not physically active. Participants are aware that physical inactivity is due to consumption of junk food. Suffice to say energy for daily activities are obtained even after the consumption of fast food.Similar study was conducted by [21, 22] where physical inactivity is the major cause for obesity is agreed by a high population as they experienced which consensus with our present study $53 \%$ agree physical inactivity causes obesity and $47 \%$ disagree.

The present study results consensus with the study by [23] where $45 \%$ agreed that consumption of junk food reduces physical activity and causes physical illness and $20 \%$ disagreed. Similar findings were seen in a study conducted by [24] where $90 \%$ agreed that physical inactivity leads to obesity and 10\% disagreed. Awareness of the chemicals present makes the population reduce the consumption at high risk. In a similar study conducted by [25] $60 \%$ agreed to control the consumption of junk food and $20 \%$ disagree with the consensus with our present study. Participants expressed health concerns strongly agreeing the factor causing obesity.

\section{Limitations}

The sample size is less and skipping meals with intake of junk food should be factored in.

\section{Future scope of study}

It helps in diagnosis related to physical inactivity and obesity. Create awareness in school going children. Nutritional education should be taught in schools.

\section{Conclusion}

The present study highlighted the association between physical inactivity and consumption of junk food leading to obesity. This survey created a basic awareness among the middle childhood and adolescent populations about the harmful effects and related physical inactivity status due to consumption of junk food which in turn leads to obesity. Thus, more awareness should be created among the population about the outcomes and risk factors of physical inactivity and consumption of junk food.

\section{References}

[1]. Menon A, Thenmozhi MS. Correlation between thyroid function and obesity. Research Journal of Pharmacy and Technology. 2016 Oct 1; 9(10): 1568.

[2]. Nandhini JT, Babu KY, Mohanraj KG. Size, Shape, Prominence and Localization of Gerdy's Tubercle in Dry Human Tibial Bones. Research Journal of Pharmacy and Technology. 2018 Aug 31; 11(8): 3604-8.

[3]. Seppan P, Muhammed I, Mohanraj KG, Lakshmanan G, Premavathy D, Muthu SJ, et al. Therapeutic potential of Mucuna pruriens (Linn.) on ageing induced damage in dorsal nerve of the penis and its implication on erectile function: an experimental study using albino rats. Aging Male. 2018 Feb 15; 1-14. PMID: 29447059.

[4]. Sriram N, Yuvaraj S. Effects of Mobile Phone Radiation on Brain: A ques- tionnaire based study. Research Journal of Pharmacy and Technology. 2015; 8(7): 867-70.

[5]. Krishna RN, Babu KY. Estimation of stature from physiognomic facial length and morphological facial length. Research Journal of Pharmacy and Technology. 2016 Nov 28; 9(11): 2071-73.

[6]. Hafeez N. Accessory foramen in the middle cranial fossa. Research Journal of Pharmacy and Technology. 2016 Nov 1; 9(11): 1880.

[7]. Keerthana B, Thenmozhi MS. Occurrence of foramen of huschke and its clinical significance. Research Journal of Pharmacy and Technology. 2016 Nov 28; 9(11): 1841-42.

[8]. Johnson J, Lakshmanan G, Biruntha M, Vidhyavathi RM, Kalimuthu K, Sekar D. Computational identification of MiRNA-7110 from pulmonary arterial hypertension (PAH) ESTs: a new microRNA that links diabetes and PAH. Hypertension Research. 2020 Apr; 43(4): 360-2.

[9]. Samuel AR, Thenmozhi MS. Study of impaired vision due to Amblyopia. Eye. 2015; 6: 14-29.

[10]. Subashri A, Thenmozhi MS. Occipital emissary foramina in human adult skull and their clinical implications. Research Journal of Pharmacy and Technology. 2016 Jun 1; 9(6): 716.

[11]. Sekar D, Lakshmanan G, Mani P, Biruntha M. Methylation-dependent circulating microRNA 510 in preeclampsia patients. Hypertens Res. 2019 Oct;42(10):1647-1648. PMID: 31114031.

[12]. Kannan R, Thenmozhi MS. Morphometric Study of Styloid Process and its Clinical Importance on Eagle's Syndrome. Research Journal of Pharmacy and Technology. 2016 Aug 28; 9(8): 1137.

[13]. Thejeswar EP, Thenmozhi MS. Educational research-iPad system vs textbook system. Research Journal of Pharmacy and Technology. 2015 Aug 1; 8(8): 1158.

[14]. Choudhari S, Thenmozhi MS. Occurrence and Importance of Posterior Condylar Foramen. LATERALITY. 2016 Aug 28; 8: 11-43.

[15]. Ghosh A, Sarkar D, Pal R, Mukherjee B. Correlates of overweight and obesity among urban adolescents in bihar, India. J Family Med Prim Care. 2015 Jan-Mar;4(1):84-8. PMID: 25810995.

[16]. Kar S, Khandelwal B. Fast foods and physical inactivity are risk factors for obesity and hypertension among adolescent school children in east district of Sikkim, India. J Nat Sci Biol Med. 2015 Jul-Dec;6(2):356-9. PMID: 26283829.

[17]. Pratha AA, Thenmozhi MS. A study of occurrence and morphometric analysis on meningo orbital foramen. Research Journal of Pharmacy and Technology. 2016; 9(7): 880-2.

[18]. Hopping BN, Erber E, Mead E, Sheehy T, Roache C, Sharma S. Socioeconomic indicators and frequency of traditional food, junk food, and fruit and vegetable consumption amongst Inuit adults in the Canadian Arctic. J Hum Nutr Diet. 2010 Oct;23 Suppl 1:51-8. PMID: 21158962.

[19]. Sharma ML. G444 (P) obesity and overweight associated risk factors, increasing problem among school children in india. Archives of Disease in Childhood. 2014 Apr 1; 99(Suppl 1): A185.

[20]. Rani VP, Vaz LS, Kusneniwar GN. Prevalence of Overweight, Obesity and Diet Related Factors among High School Children in Urban and Rural areas of Medchal Mandal, Rangareddy District.

[21]. Amruth M, Kumar A. A cross-sectional study on BMI and eating habits among students in a medical college in Kerala. Int J Community Med Public Health. 2019 Feb;6(3):1285-94.

[22]. Yeole UL, Dighe PD, Gawali PP, Adkitte RG, Gharote G. Assessment of Obesity and Factors Responsible for Obesity among School Going Children.

[23]. Straker LM, Howie EK, Smith KL, Fenner AA, Kerr DA, Olds TS, et al. The impact of Curtin University's activity, food and attitudes program on physical activity, sedentary time and fruit, vegetable and junk food consumption among overweight and obese adolescents: a waitlist controlled trial. PLoS One. 2014 Nov 6;9(11):e111954. PMID: 25375109.

[24]. Samuelson G. Physical inactivity in adolescence-an obesity risk factor. 2005; 97-97.

[25]. Azemati B, Kelishadi R, Ahadi Z, Shafiee G, Taheri M, Ziaodini H, et al. Association between junk food consumption and cardiometabolic risk factors in a national sample of Iranian children and adolescents population: the CASPIAN-V study. Eat Weight Disord. 2020 Apr;25(2): 329-335. PMID: 30311074. 